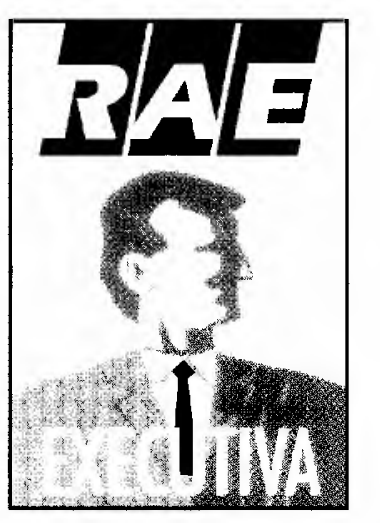

\title{
É EFICIENTE O USO DE APELOS SEXUAIS EM PROPAGANDA?
}

Um alerta para o risco da utilização do apelo sexual de forma inadequada na propaganda.

The risk of the sex appeal use in an inadequate way in advertising.

PALAVRAS-CHAVE:

Propaganda, sexo, Marketing.

KEY WORDS:

Advertising, sex, Marketing.
*Professor de Marketing do Departamento de Administração da PUC/RJ e Consultor de Empresas.

**Professor de Marketing do Departamento de Administraçāo da PUC/RJ.
Segundo resultados de pesquisa, ${ }^{1}$ a maioria dos brasileiros $(62,4 \%)$ acredita que a propaganda com apelos eróticos é a que menos atrai os telespectadores. Todavia, cenas que envolvem sexo e nudez são frequientes na televisão, tanto em anúncios como em novelas e filmes. Segundo a revista $V e j a,{ }^{2}$ em apenas uma semana contabilizou-se a presença de 1.145 cenas de nudez parciais ou totais nas quatro principais redes de televisão. Parte dessas cenas pertencem a anúncios, que recorreram ao uso de apelos sexuais para obter uma maior eficácia. Mas será que isso é verdade?

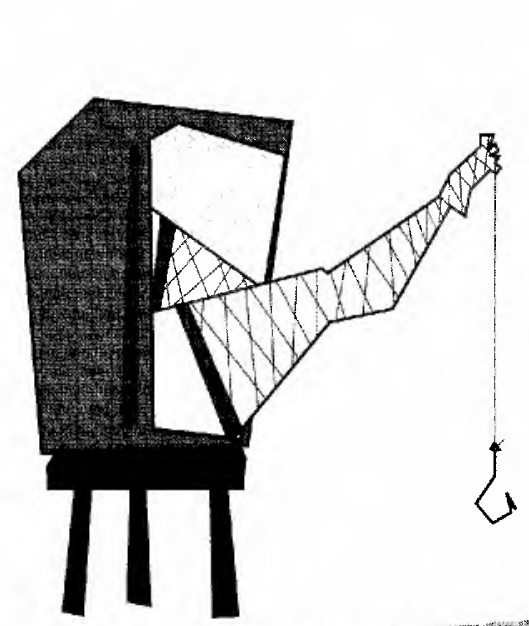

Estudos internacionais concluem que o emprego do sexo na propaganda tende a inibir a lembrança da marca, embora não se possa negar que sua utilização tenha crescido nas últimas décadas. ${ }^{3}$ Devido à freqüência com que é veiculada, a propaganda com apelo sexual provavelmente não causa, hoje, o mesmo impacto que causava na década de 60. É possível que haja um processo de aprendizagem cumulativo por parte do público, devido à re- 
petição do apelo sexual ao longo dos anos. ${ }^{4}$ teor de sexo nos anúncios pode constituir fator de distração, levando o leitor a desviar sua atenção da marca para a ilustração sexual..$^{5}$ Desse modo, tanto a aprendizagem quanto a recepção da mensagem tendem a ser prejudicadas, sendo o prejuízo tanto maior quanto maior for a distração causada pela ilustração do anúncio, já que a presença de modelos sensuais aumenta o número de pessoas que olham a ilustração sem prestar atenção no texto. ${ }^{6}$

\section{and}

Este artigo explora o tópico de modo teórico e aplicado. Ele procura esclarecer e fixar certos conceitos vinculados ao uso do sexo na propaganda, tais como os de sugestão ou apelo sexual e de congruência do apelo sexual com o produto. Apresenta, ainda, resultados de um estudo experimental, com base em modelo já utilizado, ${ }^{7}$ sobre a retenção de nomes de marcas em anúncios com temas sexuais.

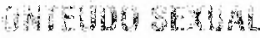

Como o conteúdo sexual em propaquanto em natureza, nas quais cabem dúvidas sobre o emprego ou não do apelo sexual, registra-se, de início, alguns conceitos relacionados ao tema. O conceito de sugestão ou apelo sexual refere-se à interpretação freudiana de que o estímulo sexual provoca idéias sobre sexo na mente do indivíduo. ${ }^{8}$ Já o conceito de congruência de apelo sexual com o produto refere-se aos elementos visuais que tenham relacionamento direto com o produto ou com a marca, sendo exigido que o produto seja sexualmente relevante. ${ }^{9}$ Existe, no entanto, a idéia de modelo decorativo, quando o objetivo do apelo sexual é não con-
Supõe-se, por outro lado, que o próprio ganda envolve diferenças, tanto em grau

gruente, e, por ser não funcional, apenas adorna o produto com um estímulo sexual ou com um atrativo.

As sugestões ou apelos sexuais mais comuns em propaganda são as visuais, envolvendo diversos graus de nudez. A variação da nude $z^{10}$ obedece a quatro dimensōes básicas: decorativa ou nula, no caso do modelo utilizar roupas do dia-adia; sedutora, no caso de blusa semi-aberta deixando transparecer os seios ou camiseta que exponha os ombros; parcialmente despida, quando se tem parte do corpo exposta; despida, no caso da exibição do corpo sem nenhuma roupa. $\mathrm{O}$ uso do sexo na propaganda, contudo, pode não se restringir a estímulos visuais, compondo-se, também, de títulos com conteúdo sexual. ${ }^{11}$

Enquanto vários pesquisadores empregam suas próprias definiçõos do que seja apelo sexual, há os que preferem deixar para os consumidores o julgamento do que seja uma conotação sexual nos anúncios utilizados em suas pesquisas. ${ }^{12}$ Nesse caso, observa-se que, apesar de o sexo na propaganda estar tradicionalmente associado à nudez, isso seria uma super-simplificação, pois outros fatores parecem influir nas percepções pessoais. Um exemplo é a maior percepção por parte das mulheres da existência de apelo sexual no texto de anúncios ou o fato de a nudez ser menos percebida pelos homens.

Deve-se ressaltar, no entanto, que na expressiva maioria, tanto dos anúncios quanto das pesquisas, o conceito de apelo sexual está associado ao uso de modelos femininos ou de textos que consideram a mulher como instrumento de tais apelos. Apesar disso, pressupõe-se que existe uma tendência mundial de tratar a mulher cada vez menos como "objeto sexual". ${ }^{13}$ Atualmente, inclusive, esse "rótulo", que no passado possuía apenas conotações pejorativas, pode envolver múltiplas dimensôes, possibilitando uma visão positiva de apelos sexuais que antes eram tidos como negativos. ${ }^{14}$

\section{Constatou-se que a lembrança da} marca foi maior nos anúncios que não utilizam sexo como apelo.

\section{A INFLUENCLA DU APELO SEXUAL SOBRE A PROPAGANOA \\ A influência do apelo sexual na percepção e avaliação de}

1. IMPRENSA, p. 60-6, ab. 1991.

2. SEXO, socos e babás, Veja, n. 26, p. $50-6$, jul. 1990

3. ALEXANDER, M. Wayne, JUDD, Ben. Do nudes in advertisements enhance brand recall? Journal of Advertising Research, v. 18, p. 47-50, Feb. 1978.

4. O'CONNOR, P. J. Recall levels of sexuality in advertising. American Marketing Association. Educators Proceedings, p. 2-5, 1986

5. BITHER, Stewart W. Effects of distraction and commitment on the persuasiveness of television advertising. Journal of Advertising Research, v. 9, p. 1 5. Feb. 1972

6. REID, Leonard N. Decorative models and the readership of magazine ads. Journal of Advertising Research, v. 23, n. 2, p. 27-32, Apr./May 1983.

7. STEADMAN, Major. How sexy illustrations affect brand recall. Journal of Advertising Research, v. 9, p. 15-9, Feb. 1969.

8. BELCH, Michael A., HOLGERSON, Barbro E., BELCH, George E. et al. Psychological and cognitive responses to sex in advertising. Advances in Consumer Research, p. 424-7, 1981.

9. Idem, ibidem.

10. Idem, ibidem.

11. SOLEY, Lawrence, KURZBARD, Gary. Sex in advertising: a comparison of 1964 and 1984 magazine advertisements. Journal of Advertising, v. 15, n. 3, p. 46-64, 1986.

12. MORRISON, Bruce John, SHERMAN, Richard C. Who responds to sex in advertising? Journal of Advertising Research, v. 12, p. 15-9, Apr. 1972.

13. LUNDSTRON, William J., SCIGLIMPAGLIA. Sex role portrayals in advertising. Journal of Marketing, v. 41, p. 72-9, Jul. 1977.

14. FERGUSON, Jill Hicks, KRESHEL, Peggy J., TINKHAM, Spencer. In the page of Ms.: sex role portrayals of women in advertising. Journal of Advertising, v. 19, n. 1, p. 40-51, 1990. 
15. STEADMAN, Major. Op. cit. 16. CHESTNUT, Robert, LA CHANCE, Charles, LUBITZ, Amy. The decorative female model: sexual stimuli and the recognition of advertisements. Journal of Advertising, v. 6, p. 11-14, Fall 1977.

17. SMITH, George H., ENGEL, Rayme. Influence of a female model on perceived characteristics of an automobile. Proceedings of the 76th Annual Convention of the American Psychological Association, $p$. 681-2, 1968.

18. BERKMAN, Harold W. Consumer behavior. Kent Publishing Company, p. 445-7, 1986

19. RICHMOND, David, HARTMAN, Timoty P. Sex appeal in advertising. Journal of $A d$ vertising Research, v. 22, n. 5 , p. 53-61. Nov. 1982.

20. STEADMAN, Major. Op. cit.

21. BAKER, Michael J., CHURCHILL Jr. Gilbert A. The impact of physically attractive models on advertising eva-juations. Journal of Marketing Research, v. 14, p. 538-55, Nov. 1977

22. KANUNGO, R. N., PANG, S. Effects of human models on perceived product quality. Joumal of Applied Psychology, v. $57, n .2$, o. $172-8,1973$.

23. BRIT, Stewart Henderson. The use and misuse of sex in advertising. Proceedings. American Marketing Association, $p$. 163-5, 1977; RICHMOND, David. Op. cit.

24. BRITT, Stewart $H$. Op. cit.

25. MITCHELL, Andrew A. The effect of verbal and visual components of advertisements on brand attitudes and attitude toward the advertisement. Journal of Consumer Research, v. 13, p. 12-24, Jun. 1986.

26. BAKER, Michael J. Op. cit; CHESTNUT, Robert. Op. cit; BRITT, Stewart H. Op. cit; O'CONNOR, P. J. Op. cit.

27. BITHER, Stewart. Op. cit.

28. PETERSON, Robert A., KERIN Roger A. The female role in advertisements: some experimental evidence. Journal of Marketing. v. 41, p. 59-63, Oct.1977.

29. GILLY, Mary C. Sex roles in advertising: a comparison of television advertisements in Australia, Mexico and the United States. Journal of Marketing, $v$. 52, p. 75-85, Apr. 1988. anúncios compõe-se de diferentes aspectos. Já se concluiu, há alguns anos, que o uso de sexo em propaganda não é eficaz. ${ }^{15}$ Estudos mais recentes corroboram tal conclusão, salientando que a presença de modelos decorativos do sexo feminino aumenta o reconhecimento do anúncio, sem, contudo, aumentar o reconhecimento da marca. ${ }^{16}$ Leva-se em conta, na explicação desse fenômeno, que o emprego de tais modelos influencia as avaliações emocionais e objetivas do produto, tanto em indivíduos do sexo masculino quanto do sexo feminino. ${ }^{17}$ Pesquisas mais recentes também revelam que as pessoas não conseguem relacionar a ilustração com o nome da marca anunciada, ${ }^{18}$ apesar das evidências empíricas de que ilustrações sexuais provocam uma reação imediata, chegando até a aumentar o interesse dos leitores de ambos os sexos. A forma pela qual se utiliza o apelo sexual pode influenciar a eficiência da propaganda. Numa comparação entre elementos de sexualidade, os anúncios que aproveitam o sexo apenas para atrair a atenção obtêm menor lembrança de marca do que os anúncios que o fazem somente de maneira simbólica. ${ }^{19}$

O apelo sexual se apresenta mais fundamentado nas pesquisas pela sua congruência com a marca ou com o produto anunciado. A congruência constitui uma relação lógica entre um modelo sensual e o produto, o que faz o apelo sexual aumentar a lembrança da marca. ${ }^{20} \mathrm{Se}$, através de uma relação pessoal entre modelo e mensagem, um modelo fisicamente atraente aumentar a credibilidade da mensagem que está sendo veiculada, a eficiência da comunicação também será aumentada, embora a atratividade física não produza maiores efeitos cognitivos e comportamentais. ${ }^{21}$ Isso pode ocorrer também na percepção do consumidor com relação ao produto ser masculino ou feminino, realçando uma relação lógica entre o produto e o sexo do modelo empregado..$^{22}$

Estudos indicativos de que a lembrança de marca tende a ser mais constatada nos casos em que os apelos sexuais demons- tram congruência com o produto, ${ }^{23}$ salientam que o apelo sexual não contribui para ajudar o anúncio a cumprir o seu papel de promover o produto ou serviço, caso o uso do sexo não seja feito de forma apropriada. ${ }^{24} \mathrm{~A}$ incongruência interfere na comunicação, pois a recepção da mensagem e a aprendizagem tendem a ser prejudicadas quanto maior for a distração causada pela ilustração do anúncio. Uma ilustração com apelos sexuais, quando constitui elemento visual incongruente com o produto ou marca anunciados, distrai a audiência, reduzindo o número de pensamentos sobre o produto e diminuindo a quantidade de informação sobre seus atributos. ${ }^{25}$

Vários autores ${ }^{26}$ notam a possibilidade de efeitos negativos quanto ao uso inadequado do sexo na propaganda, pois um estímulo fora do normal pode levar à dissociação da ilustração com a marca. Quando a audiência discorda dos elementos de distração, ela contra-argumenta o esforço de persuasão do anúncio como meio de defesa de seus pontos de vista previamente estabelecidos. ${ }^{27}$ É possível também que a audiência associe o uso do sexo à qualidade do produto. De fato, vários registros que associam a nudez num anúncio com a baixa qualidade e reputação do produto anunciado parecem corroborar tal hipótese. Por outro lado, anúncios com modelos sedutores sem estarem despidos são considerados como de maior apelo publicitário, e os produtos por eles veiculados não só são considerados de maior qualidade, como também provenientes de empresas de melhor reputação. ${ }^{28}$

É logicamente aceitável, como já foi registrado, ${ }^{29}$ que os contextos sociais reflitam, de maneira diferenciada, o apelo sexual exposto, particularmente no que diz respeito ao papel social atribuído a cada sexo e ao modo como esse papel é mostrado nos anúncios. Um estudo compa- 
rativo dos papéis representados pela mulher na propaganda brasileira classifica como objeto sexual o papel desempenhado pelo elemento humano para corporificar a promessa explícita do produto com maior atratividade para o sexo oposto. ${ }^{30}$

A atratividade do modelo, quando se emprega ilustração fotográfica, pode ser relacionada ao envolvimento do público com o anúncio. ${ }^{31}$ No entanto, embora sexo e atratividade física de um modelo publicitário possam influenciar a avaliação dos indivíduos em relação à estética de um anúncio, chamar a atenção e prender a audiência, essas variáveis parecem não afetar as cognições dos indivíduos, podendo até serem consideradas relativamente incficientes na aceitação da mensagem. ${ }^{32}$ Mesmo assim, o emprego de mulheres atraentes em poses sugestivas pode, em alguns casos, chocar a audiência, pela violação de normas sociais. ${ }^{33}$

Finalmente, embora se empregue modelos do sexo oposto ao do consumidor da marca anunciada, para chamar a atençāo sobre o anúncio, já se registrou que o público-alvo, na maioria dos casos, tende a ser mais influenciado por modelos do mesmo sexo. ${ }^{34}$

\section{O ESTUDO}

Este estudo tenta estender para o contexto brasileiro a pesquisa realizada por Steadman, ${ }^{35}$ na qual foram apresentadas propagandas do tipo "mulher objeto" para um público exclusivamente masculino, medindo-se a eficiência do anúncio pela lembrança da marca. No contexto brasileiro, procurou-se ampliar as hipóteses levantadas por Steadman e levar o estudo a termo considerando-se um público-alvo composto tanto de homens quanto de mulheres. Desse modo, formularam-se três questões, posteriormente tratadas como hipóteses de teste, a saber:

1. A lembrança da marca é maior em anúncios que utilizam sexo como apelo?

2. A lembrança da marca é maior em anúncios em que o apelo sexual é congruente com o produto promovido?

3. A lembrança da marca em anúncios que empregam apelo
sexual é maior entre os homens do que entre as mulheres?

Admite-se, aqui, a lembrança da marca como medida de eficiência da propaganda, já empregada por diversos outros autores. ${ }^{36}$ Para testar as hipóteses foram empregados slides (produzidos profissionalmente) e questionários que obedeciam a critérios já empregados $\mathrm{cm}$ pesquisas semelhantes. ${ }^{37}$

\section{O MÉTODO}

O método pode ser descrito $\mathrm{cm}$ cinco etapas, a saber:

Etapa 1: determinação do que é apelo sexual

Os pesquisadores criaram 60) bases de anúncios com e sem apelo sexual a partir de ilustrações colhidas em diversas revistas estrangeiras de baixa circulação no país. Um júri composto de três pessoas selecionou dez ilustrações sem qualquer tipo de apelo sexual e dez ilustrações que, definitivamente, continham apelo sexual.

\section{Os resultados mostram ainda que as mulheres tiveram uma melhor lembrança de marca ...}

30. SCHIMIDT, Angela. Estereótipos femininos na propaganda brasileira: 1975-1981. Relatório técnico, n. 38, Coppead/UFRJ.

31. BAKER, Michael J. Op. cit., KAHLE, Lynn R., HOMER, Pamela M. Physical attractiveness of the celebrity endorser: a social adaptation perspective. Journal of Consumer Research, v. 11, p. 954-61, 1985.

32. BAKER, Michael J. Op. Cit.

33. PATZER, Gordon L. The physical attractiveness phenomena. New York: Plenum Press, 1985.

34. CABALLERO, Marjorie J., SOLOMON, Paul J. Effects of model attractiveness on sales responses. Journal of Advertising. v. 13, n. 1, p. 17-33, 1984.

\section{STEADMAN, Major. Op. Cit.}

36. STEADMAN, Major. Op. cit; BRITT, Stewart W. Op. cit: CHESTNUT, Robert. Op. cit; SINGH, Surendra N. ROTHSCHILD, Michael L., CHURCHILL Jr., Gilbert A. Recognition versus recall as measures of television comercial forgetting. Joumal of Marketing Research, v. 25, p. 72-80, Feb. 1988.

37. CHESTNUT, Robert. Op. cit; MITCHELL, Andrew A. Op. cit. 
Apelo sexual e congruência com a marca - classificação segundo o júri

Série 1 - Parte A:cinco ilustrações com apelo sexual e alta congruência com a marca;

- Parte B: cinco ilustrações sem apelo sexual e com alta congruência com a marca;

Série 2 - Parte A:cinco ilustrações com apelo sexual e baixa congruência com a marca;

- Parte B: cinco ilustrações sem apelo sexual e com baixa congruência com a marca.

selecionadas as dez marcas mais citadas, de modo a evitar o uso de marcas pouco conhecidas.

Etapa 3: associação das marcas com as ilustrações

O mesmo júri da etapa 1 criou duas séries compostas de duas partes cada uma, de acordo com o critério de congruência, como mostra o quadro 1 (ver quadro 1).

Assim, obteve-se duas séries com as dez marcas selecionadas na etapa anterior de modo que, apesar de ambas as séries

dois slides a cada série, um no início e outro no fim, para evitar que os slides colocados nos extremos da apresentação ficassem em destaque. Esses slides não foram objeto de mensuração.

\section{Etapa 5: execução do teste}

Os slides foram projetados para dois grupos, um de 76 e outro de 57 pessoas de ambos os sexos, com idades variando de 18 a 25 anos, que estavam participando de cursos de treinamento gerencial promovidos por duas instituições da cidade do Rio de Janeiro. $O$ tempo de projeção de cada slide foi de cinco segundos, o mesmo utilizado em pesquisa semelhante. ${ }^{38}$ Antes da projeção, os participantes foram levados a crer que estavam assistindo a uma palestra sobre propaganda. No

terem sido compostas pelas mesmas marcas, cada uma continha ilustrações e apelos diferentes. Convém ressaltar que foram consideradas apenas as associações que obtiveram unanimidade do júri.

\section{Etapa 4: composição dos slides}

Tomando-se por base as duas séries, foram produzidas duas versões de slides, uma com o nome da marca e a outra sem o nome da marca, o qual aparecia no canto inferior à direita de cada slide. $\mathrm{O}$ nome da marca tinha sempre o mesmo tamanho de corpo de letra e cor (letras pretas sobre fundo branco), e ocupava cerca de $5 \%$ do espaço dos anúncios. Foram adicionados início da "palestra" explicou-se que seriam projetados uma série de slides para uma melhor compreensão do tema, e pediu-se que não fossem feitos quaisquer comentários nos dois minutos iniciais de projeção. Os participantes concordaram prontamente com tais exigências.

Imediatamente após a projeção dos doze slides, o professor "distraiu" os participantes por cerca de trinta minutos com uma segunda projeção de anúncios. Nessa etapa, os anúncios não continham apelo sexual; eram reproduções de anúncios reais e sujeitos a comentários dos participantes. Esse procedimento serviu para dissimular o objetivo, pois focalizou a 
questão do envolvimento com o produto e a natureza dos textos na propaganda.

Após esses trinta minutos, os participantes reviram a seqüência anterior de doze slides, só que sem a identificação das marcas. Cada um recebeu um questionário no qual anotava-se o suposto nome da marca, conforme a seqüência que lhes era apresentada.

\section{RESULTADOS}

Após a contagem das respostas, segundo a classíficacão do apelo da ilustração em sexual e não sexual, obteve-se os resultados gerais apresentados a seguir. Os resultados foram submetidos ao teste do qui-quadrado atingindo nível de significância inferior a 0,05.

Constatou-se que a lembrança da marca foi maior nos anúncios que não utilizam sexo como apelo (ver tabela 1). Esse resultado corrobora outros obtidos em nível internacional, que sustentam que o apelo sexual parece servir mais para distrair do que para informar. Segundo esses estudos internacionais, o apelo sexual capta a atenção da audiência por meio da ilustração, mas, ao mesmo tempo, distrai ou retira tal atenção da marca em foco. É possível, no entanto, que o nível de lembrança se elevasse, caso o tempo de observação do anúncio fosse maior. É possível, também, formular a hipótese restritiva de que anúncios com apelos sexuais são observados por mais tempo do que aqueles que não contenham esse tipo de apelo.

A constatação das hipóteses acima exigiria outro tipo de experimento, o que

\begin{tabular}{|c|c|c|}
\hline \multicolumn{3}{|c|}{ Tabela 1: Lembrança das marcas } \\
\hline \multicolumn{3}{|c|}{ Apelo da ilustração } \\
\hline & Nagro sexuad & Sexual \\
\hline lembrades & 203 & 330 \\
\hline $\begin{array}{l}\text { Matcas } \\
\text { lembrados }\end{array}$ & 462 & 335 \\
\hline
\end{tabular}

deveria levar em conta que cada membro da audiência seguisse algum tipo de processo para retenção das informações de um anúncio, tais como: vê o anúncio; vê a marca anunciada; associa ou não a marca a outros elementos do anúncio, e retém o nome da marca e/ou outros conteúdos do anúncio.

Quando se emprega o apelo sexual em situações de não congruência, o número de marcas lembradas é inferior ao de marcas nāo lembradas. Por outro lado, em

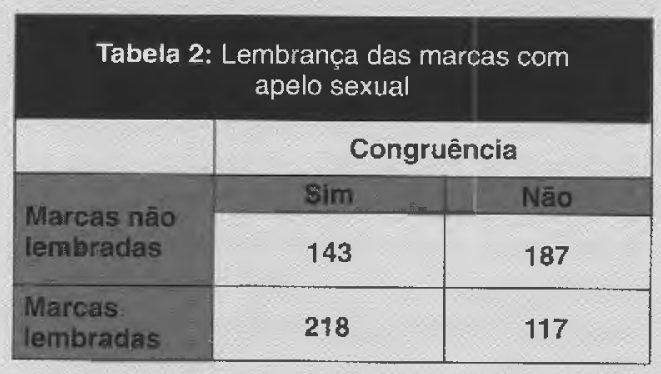

situações de congruência, o número de marcas lembradas é superior, como pode ser verificado na tabela 2 (ver tabela 2).

É possível que a capacidade de lembrar o nome da marca dependa tanto da quantidade de informação e da congruência, quanto do tipo de apelo empregado ${ }^{39} \mathrm{O}$ sexo na propaganda tende a produzir níveis adequados de lembrança quando congruentes com marca ou produto, como no caso de anúncios de roupas íntimas ou de higiene pessoal ${ }^{40}$ Além disso, mesmo os anúncios com temas não sexuais, mas. com alta congruência, favorecem a lembrança da marca. ${ }^{41}$

Os resultados mostram ainda que as mulheres tiveram uma melhor lembrança de marca, pois elas parecem apresentar um menor grau de distração ou interesse por modelos de seu próprio sexo e, em decorrência disso, redirecionam sua atenção para o nome das marcas. ${ }^{42}$ É possível, também, que as mulheres se sintam ofendidas quando apresentadas como "objetos sexuais" nos anúncios, mas, paradoxalmente, acabam tendo maior lembrança das marcas desses anúncios do que os homens (ver tabela 3).

\begin{tabular}{|l|c|c|}
\hline \multicolumn{3}{|c|}{ Tabela 3: $\begin{array}{c}\text { Lembrança das marcas com } \\
\text { apelo sexual }\end{array}$} \\
\hline \begin{tabular}{l|c|c|} 
Marcas nāo \\
lembradas
\end{tabular} & 220 & 112 \\
\hline $\begin{array}{l}\text { Marcas } \\
\text { lembradas }\end{array}$ & 177 & 139 \\
\hline
\end{tabular}

39. PLÁ, Daniel R. Sexo na propaganda e lembranca de marca Rio de Janeiro: PUC/RJ, 1990.

40. RICHMOND, David. Op. cit.

41. PLÁ, Daniel R. Op., cit.

42. AL EXANDER, M. Op. cit.

RAE - v. $34 \cdot$ ก. $4 \cdot$ Jul./Ago. 1994 
43. SEVERN, Jessica, BELCH, George E., BELCH, Michael A. The effects of sexual and nonsexual advertising appeals and information level on cognitive processing and communication effectiveness. Journal of Advertising, v. 19, n. 1, p. 1422, 1990.

44. MORRISON, Bruce John. Op. cit.

45. BAKER, Michael J. Op. cit.
Esta pesquisa, somada a outras já realizadas, alerta para o risco da utilização do apelo sexual de forma inadequada na propaganda. O sexo chama a atenção, mas também distrai, e, mesmo que para alguns seja gratificante, ${ }^{43}$ a lembrança da marca $c$ a imagem do produto podem ser prejudicadas. É possivel que o uso do apelo sexual de forma aberta ou direta promova o sexo em vez de promover o produto ou serviço. Por outro lado, se os indivíduos tiverem mais tempo para observar o anúncio do que o verificado neste estudo, é possível que ocorra o efeito inverso, isto é, maior lembrança das marcas com apelo sexual. Essa suposição baseia-se na hipótese de que as pessoas olham mais tempo os anúncios com sexo, e talvez não dêem atenção aos anúncios sem conteúdo

ca, atitude cm relação ao anúncio ou em relação à marca, ou intenção de compra.

Tal como em outros estudos, ${ }^{14}$ neste os homens tiveram menor lembrança de marca do que as mulheres. Vale a pena analisar esse resultado em maior profundidade, já que os homens tiveram menor lembrança de marca inclusive nos anúncios sem apelo sexual.

É possível que esse fenômeno seja resultado de um menor grau de distração ou interesse das mulheres pelo apelo sexual de modelos do scu próprio sexo.

Como foi mencionado, elas podem se sentir ofendidas quando apresentadas como "objeto sexual" en anúncios como os utilizados nesta pesquisa. Para confirmar tal hipótese, seria interessante, então, reformular este estudo, utilizando modelos predominantemente do sexo masculino.

Para gerentes de marketing, no que tange ao processo de percepção do consumidor, o que importa é descobrir as "pistas" que as pessoas utilizam na percepção de um anúncio. A combinação dessas "pistas" forma a impressão e o significado que uma pessoa tem de um anúncio. ${ }^{45}$ Isso pode depender também da atitude do indivíduo em relação ao sexo ou à sexual. No entanto, convém ressaltar que não há evidências na literatura pertinente que corroborem tal hipótese.

Esta pesquisa chama atenção para o fato de que a lembrança de marca tende a ser maior nos anúncios que não utilizam o sexo como apelo, e isso parece ocorrer tanto na situação de alta congruência, quanto na de baixa congruência. Na situação de baixa congruência, a lembrança de marca tende a ser $76,3 \%$ maior, quando não se utiliza o apelo sexual, enquanto que na situação de alta congruência essa diferença é de apenas $16,4 \%$.

O conteúdo sexual e a congruência do apelo com a marca talvez interfiram de forma distinta no processo acima. O efeito desses dois elementos na eficiência da propaganda depende do critério que se utiliza para avaliar essa eficiência: lembrança de marca, reconhecimento de mar-

marca que utilizou como apelo, pois certos estudos afirmam que a atitude favorável ao sexo leva as pessoas a uma avaliação mais favorável da marca anunciada. A realização de experiências semelhantes a essa, junto a grupos menos homogêneos, talvez permitisse uma melhor generalização dos resultados, acrescentando variáveis de atitude sobre a lembrança de marca.

Em síntese, pode-se dizer que atrair a atenção simplesmente não é motivo suficiente para justificar o uso do apelo sexual na propaganda. Os resultados desta pesquisa indicam que o mais importante é esse apelo ser relevante para a imagem do produto ou serviço. $O$ uso do apelo sexual provavelmente serve mais para distrair do que para obter a lembrança da marca anunciada, sendo, contudo, mais eficaz em condição de congruência. .l 